\title{
Impedimetric Detection of Histamine in Bowel Fluids Using Synthetic Receptors with pH-Optimized Binding Characteristics
}

\author{
Marloes Peeters ${ }^{*}{ }^{\dagger}$ Freddy J. Troost, ${ }^{\ddagger}$ Roel H.G. Mingels, ${ }^{\dagger}$ Tina Welsch, ${ }^{\S}$ Bart van Grinsven, ${ }^{\dagger}$ \\ Tom Vranken, ${ }^{\dagger}$ Sven Ingebrandt, ${ }^{\S}$ Ronald Thoelen, ${ }^{\dagger, \perp}$ Thomas Jan Cleij, ${ }^{\dagger}$ and Patrick Wagner ${ }^{\dagger}, \mathbb{\Phi}$ \\ ${ }^{\dagger}$ Institute for Materials Research, Hasselt University, Wetenschapspark 1, 3590 Diepenbeek, Belgium \\ ${ }^{\ddagger}$ Department of Internal Medicine, div. of Gastroenterology-Hepatology, Maastricht University Medical Center, Minderbroedersberg \\ 4-6, 6211 LK Maastricht, The Netherlands \\ ${ }^{\S}$ Fachhochschule Kaiserslautern, University of Applied Sciences, Amerikastraße 1, 66482 Zweibrücken, Germany \\ ${ }^{\perp}$ XIOS University College Limburg, Agoralaan - Building H, 3590 Diepenbeek, Belgium \\ IIIMEC vzw, division IMOMEC, Wetenschapspark 1, 3590 Diepenbeek, Belgium
}

\section{Supporting Information}

\begin{abstract}
Histamine is a biogenic amine that is indispensable in the efficient functioning of various physiological systems. In previous work, a molecularly imprinted polymer (MIP) based sensor platform with impedimetric readout was presented which could rapidly and at low cost determine histamine concentrations in buffer solutions within pH 7-9. ${ }^{1,2}$ For diagnostic applications, histamine should be detectable in a wider $\mathrm{pH}$ range as it mostly occurs in mildly acidic environments. To understand this $\mathrm{pH}$-dependent response of the MIP sensor, we propose a statistical binding
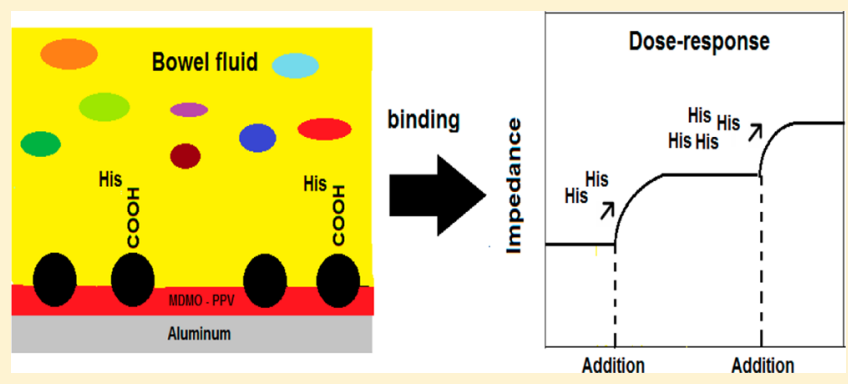

performance of MIP based on acrylic acid in the required $\mathrm{pH}$ range and verify these results experimentally by UV-vis spectroscopy, microgravimetry, and impedance spectroscopy. Using impedimetric read-out, specific and selective detection of histamine in the physiologically relevant nanomolar concentration range is possible in neutral and mildly acidic phosphate buffer. Finally, this sensor platform was used to analyze the histamine concentration of mildly acidic bowel fluid samples of several test persons. We show that this sensor provides reliable data in the relevant concentration regime, which was validated independently by enzyme-linked immuno sorbent assay (ELISA) tests.
\end{abstract}

$\mathrm{H}$ istamine is an organic nitrogen compound which was first described in 1910 by Henry H. Dale and P. P. Laidlaw ${ }^{3}$ (Figure S-1, Supporting Information). It is produced from the decarboxylation of the amino acid histidine by the enzyme histidine decarboxylase. This reaction takes place in the mast cells and basophils ${ }^{4,5}$ where histamine is detained in intracellular granules. ${ }^{6}$ In mast cells isolated from the lung, skin, and the small intestine, approximately 3-8 pg histamine/cell is found. ${ }^{7}$ When the mast cells are exposed to allergens, histamine is released and the local concentration is increased resulting in an allergic reaction. ${ }^{8}$ Another important site of histamine storage and release are the enterochromaffin-like cells in the stomach and intestines. There, histamine is involved in regulating the physiological function of the gut. ${ }^{6}$ Furthermore, a high concentration of histamine $(1-6 \mu \mathrm{mol} / \mathrm{kg})$ is present in the brain where it acts as a neurotransmitter. ${ }^{9}$

Histamine is naturally present in many fruits, vegetables, beer, red wine, cheese, and fish. ${ }^{10}$ The concentration is relatively low; however, when food is spoiled, the amount can increase to toxic levels up to $50 \mathrm{mg}$ per $100 \mathrm{~g}$ of product, causing food poisoning. ${ }^{10}$ Histamine detection is therefore of great importance for the food industry and food safety. Another area of substantial interest is biomedical research since histamine plays a pivotal role in the irritable bowel syndrome (IBS) ${ }^{11,12}$ allergies, ${ }^{8}$ asthma, ${ }^{13}$ rheumatoid arthritis, and related diseases. ${ }^{14}$ For these type of medical applications, the detection limit should be considerably lower than in the case of food analysis: in, e.g., blood, the normal physiological concentration ranges from 200 to $600 \mathrm{nM}^{15}$

The most common techniques to detect histamine are highperformance liquid chromatography (HPLC), ${ }^{16}$ gas chromatography (GC), ${ }^{17}$ or enzyme-linked immuno sorbent assay (ELISA), ${ }^{18}$ all of which are laborious and expensive. Electrochemical techniques are inexpensive; however, the use of these techniques is limited due to the high oxidation potential $(\sim 1.2$ $\mathrm{V}$ ) of histamine. ${ }^{19}$ In phosphate buffer of $\mathrm{pH} 7.1$, a detection limit of $20 \mu \mathrm{M}$ was established with a diamond electrode using amperometric detection. ${ }^{20}$ This concentration is well above the

Received: September 11, 2012

Accepted: December 18, 2012

Published: December 18, 2012 


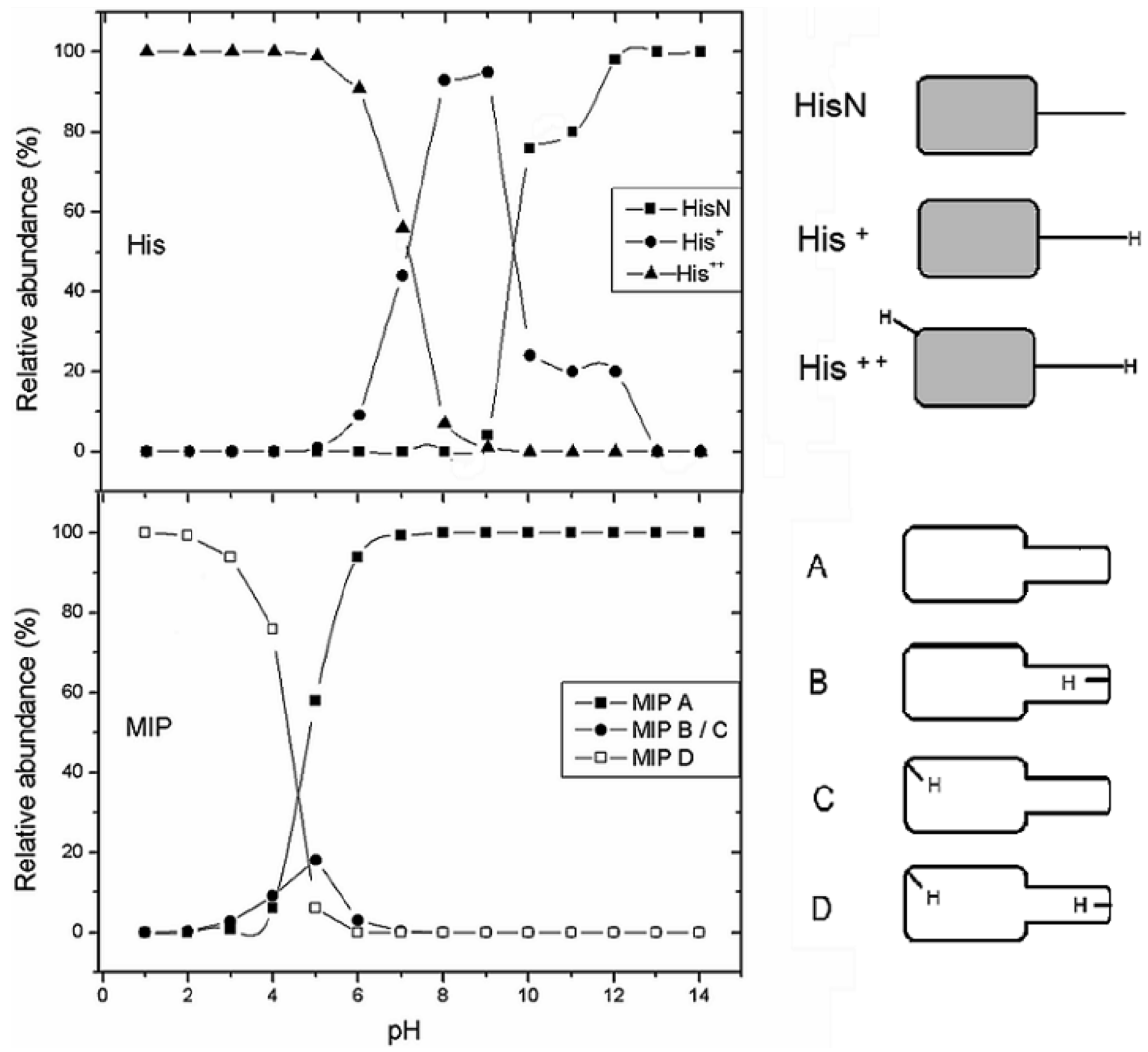

Figure 1. Schematic representations of the protonation states of histamine (above) and of MIP conformations A-D (below) in pH range of 1-14. Within $\mathrm{pH}$ range $1-4, \mathrm{His}^{+2}$ is the abundant form of histamine while this is MIP D for the MIP conformations. His ${ }^{+}$dominates from $\mathrm{pH} 7$ to 9 . At higher $\mathrm{pHs}$, HisN will take over. The results for histamine were adopted from literature. ${ }^{1}$ For the MIPs, MIP A is the abundant species starting from $\mathrm{pH} 5$.

physiologically relevant concentration, and further on, no tests were performed yet in biological samples.

In vitro measurements were performed by Bitziou et $\mathrm{al}^{20,21}$ who used boron-doped diamond microelectrodes in amperometric mode to detect histamine release from ECL cells and from gastric mucosa of the guinea pig stomach. The sensor was proven to be stable, and the signal was not influenced by other electroactive components such as serotonin, which makes it suitable for qualitatitve measurements in vitro. However, quantitative measurements were not performed yet. So far, first attempts to an in vivo measurement of histamine were made by Mochizuki et al. and Itoh et al. ${ }^{22,23}$ They could make an estimate of the histamine release in the hypothalamus of anesthetized rats by in vivo microdialysis coupled to HPLC equipment with a fluorescence detector. Upon administration of histamine agonists, an increase in the release rate was observed. However, this technique cannot be directly transferred to measurement in vivo in humans, and furthermore, no reference tests with analogous molecules were performed to demonstrate the selectivity of the sensor platform.

Molecularly imprinted polymers (MIPs) present an interesting alternative to these more traditional techniques of histamine detection. MIPs are synthetic receptors with imprinted nanocavities that are able to rebind their target molecule as specific and selective as an enzyme. ${ }^{24-26}$ Their use offers several benefits: First, MIPs can be synthesized at a rather low cost via established polymer-chemical routes. ${ }^{27,28}$ Second, MIPs are robust and can withstand extremes of heat and $\mathrm{pH}^{29,30}$ Third, MIPs prepared according to the noncovalent approach have the potential of being regenerated. ${ }^{31}$ Until now, there are only a few reports in the literature about MIPs for histamine recognition; Tong et al. reported on a MIP based sensor where $\operatorname{zinc}(\mathrm{II})$-protoporphyrin $(\mathrm{ZnPP})$ was used as a fluorescent monomer and detection was in the millimolar range. ${ }^{32}$ Allender et al. studied various MIPs for pharmaceutical applications, including MIPs for histamine. A histamine MIP was prepared with the monomer methacrylic acid, and detection was subsequently performed with HPLC columns. ${ }^{33}$ Pietrzyk et al. synthesized a MIP by electropolymerizing polypyrrole, and a detection limit of $20 \mu \mathrm{M}$ was reached in phosphate buffer with an amperometric sensor. ${ }^{34}$ The first MIP sensor setup capable of measuring the physiologically relevant nanomolar concentration range has been developed recently by Bongaers et al. and Horemans et al. ${ }^{1,2}$ These measurements were all performed in buffer solutions, and for future applications, biological samples are considerably more interesting. The MIP used in these publications was composed of methacrylic acid (MAA) as functional monomer, ethylene glycol dimethacrylate (EGDM) as cross-linker, and dimethylsulfoxide (DMSO) as porogen. After bulk polymerization, particles were ground and fixated onto electrodes using a polymer adhesive. Subsequently, detection down to the nanomolar concentration range could be performed by impedance spectroscopy. In the micromolar range, the quartz crystal microbalance $(\mathrm{QCM})^{35}$ proved to be most useful. While histamine could be measured specifically and selectively at $\mathrm{pH}$ 7 , at mildly acidic pHs, no binding was observed which is due to the protonation behavior of the target molecule and the MIP. This $\mathrm{pH}$ dependence was also reported by Trikka et al., which used a histamine MIP with exactly the same composition, but as 


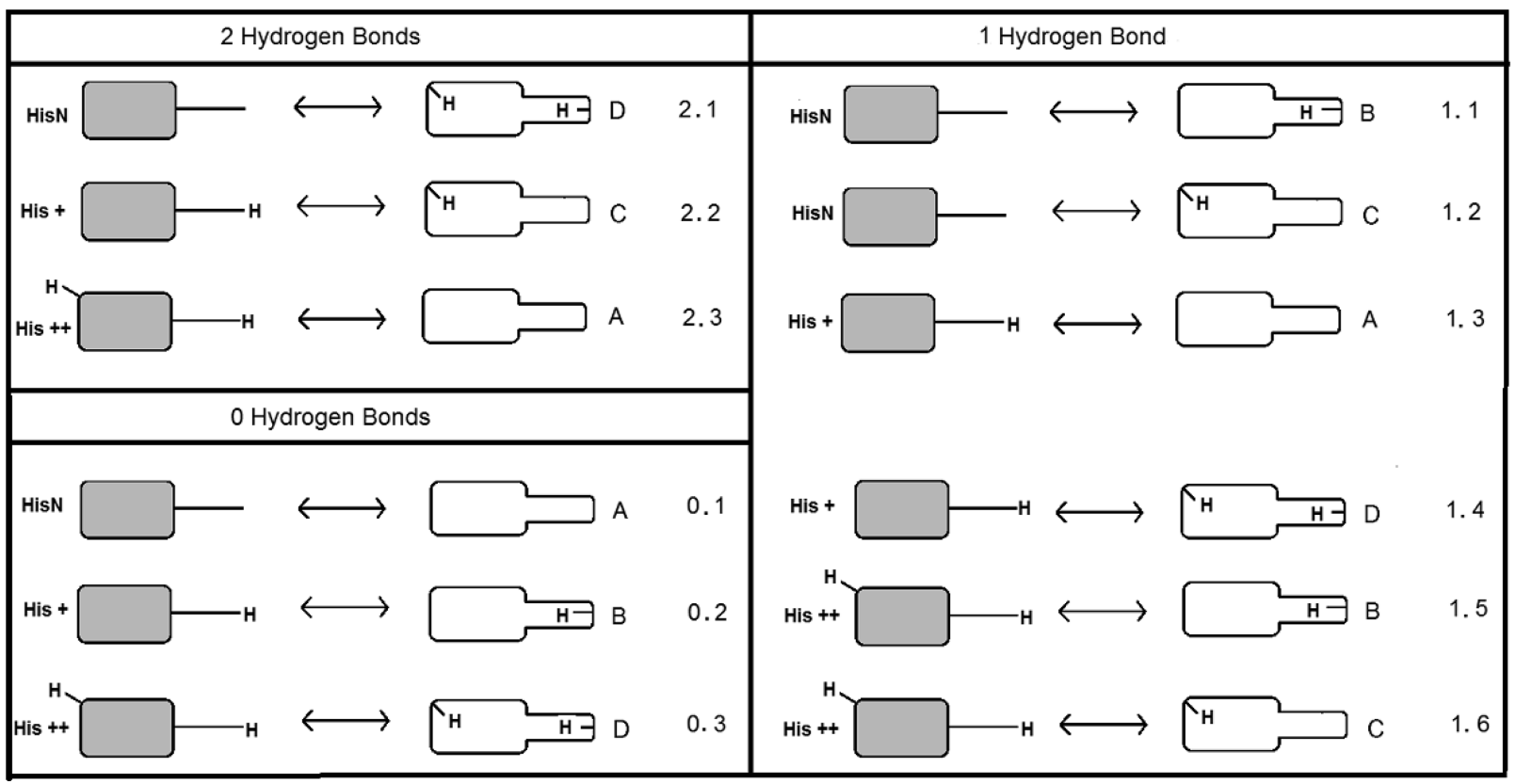

Figure 2. Overview of situations in which 0,1 , and 2 hydrogen bonds can be formed.

a detection method, a colorimetric assay was used. ${ }^{36}$ In the $\mathrm{pH}$ Model section, we will now propose a statistical binding model to explain this $\mathrm{pH}$-dependent sensor response.

pH Model. We are interested in measuring histamine in the gastro-intestinal tract, where the $\mathrm{pH}$ of the fluids varies between 5 and $8 .{ }^{37}$ The functional monomer MAA, which was used by Bongaers et al. and Horemans et al., is present in the neutral $(\mathrm{COOH})$ and deprotonated form $\left(\mathrm{COO}^{-}\right)$depending on the $\mathrm{pH}$ of the solution. ${ }^{1,38}$ At $\mathrm{pH} 5$, which is well below the $\mathrm{p} K_{\mathrm{a}}$ (6.5) of MAA, the acid occurs mostly in the neutral form. ${ }^{38}$ The target, histamine, occurs in three natural forms; the neutral form (HisN), the single protonated state $\left(\mathrm{His}^{+}\right)$, and the double protonated state $\left(\mathrm{His}^{+2}\right)$. $\mathrm{Up}$ to a $\mathrm{pH}$ of 10 , the protonated states are abundant, at higher $\mathrm{pH}$ values, the neutral form will dominate. The relative abundances are illustrated in Figure $1 .^{1}$

For the formation of a hydrogen bond, there should be a hydrogen bond donor and a hydrogen bond acceptor. In the case of the functional monomer, the neutral methacrylic acid $(\mathrm{COOH})$ form is a donor. The protonated histamine is also a donor, and as a result, no hydrogen bonds can be formed which makes binding to the target unlikely at a $\mathrm{pH}$ of 5 . For binding to occur, the monomer should be an acceptor, which is the case in the deprotonated $\left(\mathrm{COO}^{-}\right)$state. To obtain a functional monomer which is mostly in the deprotonated state at $\mathrm{pH} 5$, the monomer should be more acidic than MAA and the $\mathrm{p} K_{\mathrm{a}}$ value should be lower. Therefore, acrylic acid (AA) was selected, which has a $\mathrm{p} K_{\mathrm{a}}$ value of approximately $4.5 .{ }^{39}$ With the following calculations, we will demonstrate that MIPs based on AA monomers are able to bind histamine at mildly acidic $\mathrm{pHs}$ which is not possible to achieve with MAA as monomer.

Histamine contains two functional sites for hydrogen bond formation, namely, the amine group and the nitrogen in the ring next to the double bond. To correct for these two binding sites, already during the synthesis, two times the amount of monomer compared to the target was used. The monomer can be either in the neutral or the deprotonated state and, since per target molecule two monomers are available, this results into four possible MIP conformations. They are labeled from A to D
(Figure 1). Situation A represents two functional monomers in the deprotonated state, while for situation $\mathrm{D}$ both monomers are in the neutral form. In the cases of B and C, there is one monomer in the neutral and the other in the deprotonated state. In total, the sum of situations A, B, C, and D is $100 \%$. The relative abundance of the states is determined by the Henderson-Hasselbach equation (eq 1):

$$
\mathrm{pH}=\mathrm{p} K_{\mathrm{a}}+\log \frac{[\mathrm{COOH}]}{\left[\mathrm{COO}^{-}\right]}
$$

As derived from this formula, situations $\mathrm{B}$ and $\mathrm{C}$ can be calculated by multiplying the percentage of $\mathrm{COOH}$ present by that of $\mathrm{COO}^{-}$. Directly resulting from this, $\mathrm{A}$ and $\mathrm{D}$ are equal to the squared percentage of $\mathrm{COO}^{-}$or $\mathrm{COOH}$, respectively. For example, at $\mathrm{pH} 5$, the percentage of $\mathrm{COO}^{-}$is $76 \%$ and that of $\mathrm{COOH}$ is $24 \%$. The occurrence of MIP $\mathrm{A}$ is then equal to $76 \%$ squared, which is $58 \%$. For the occurrence of MIP D, this corresponds to $6 \%$. The other remaining $36 \%$ is equally divided over MIP B and C; therefore, both are present at $18 \%$. The results for $\mathrm{pH} 1-14$ are shown in Figure 1 and in Table S-1 and Table S-2 of the Supporting Information.

For histamine to bind to the MIP, at least one, but preferably two, hydrogen bonds should be formed. The situations in which two hydrogen bonds, one hydrogen bond, and no hydrogen bonds are established are shown in Figure 2 .

To estimate the probability of hydrogen bond formation, the probability of the independent events needs to be multiplied and subsequently summed up. This corresponds to the following formula (Supporting Information, page S-1, eq 2):

$$
\begin{gathered}
\text { prob }(n \text { hydrogen bondslpH }=k) \\
=\sum_{(i, j) \in S_{n}}=P_{\mathrm{His}}(i \mid k) P_{\mathrm{MIP}}(j \mid k)
\end{gathered}
$$

In this formula, $P_{\mathrm{His}}$ represents the probability of $\mathrm{His}^{+2}$, $\mathrm{His}^{+}$, and HisN at $\mathrm{pH}=k$ (Table S-1, Supporting Information). $P_{\mathrm{MIP}}$ is the probability of MIP A, B, C, and D at $\mathrm{pH}=k$ (Table S-2, Supporting Information). The probability of hydrogen bond 
formation from $\mathrm{pH} 1$ to 14 is shown in Table S-3, Supporting Information. As an example, we calculate the probability of the formation of two hydrogen bonds at $\mathrm{pH}$ 6. At this $\mathrm{pH}$, histamine is for $91 \%$ in the $\mathrm{His}^{+2}$ state and $9 \%$ in the $\mathrm{His}^{+}$state, and HisN is not encountered. Therefore, options 2.1, 0.1, 1.1, and 1.2 (Figure 2) do not have to be taken into account. The probability of formation of 2 hydrogen bonds is equal to 2.2 and 2.3 summed up. For option 2.2, the probability of His ${ }^{+}$ (9\%) needs to be multiplied by the probability of MIP C (3\%), resulting in a $0.3 \%$ probability. For option 2.3 . His $^{+2}(91 \%)$ is multiplied by A (94\%), which leads to $85.5 \%$ probability and, in total, a probability of the formation of 2 hydrogen bonds of $85.8 \%$. Subsequently, the probability of 1 hydrogen bond formation is $13.9 \%$, and the probability of 0 hydrogen bonds is $0.3 \%$.

The probability of binding in the $\mathrm{pH}$ range of $1-14$ was calculated for the MIP with MAA monomers and for the developed MIP based on AA monomers (Figure 3). The results of AA are shown in Table S-3 of the Supporting Information.

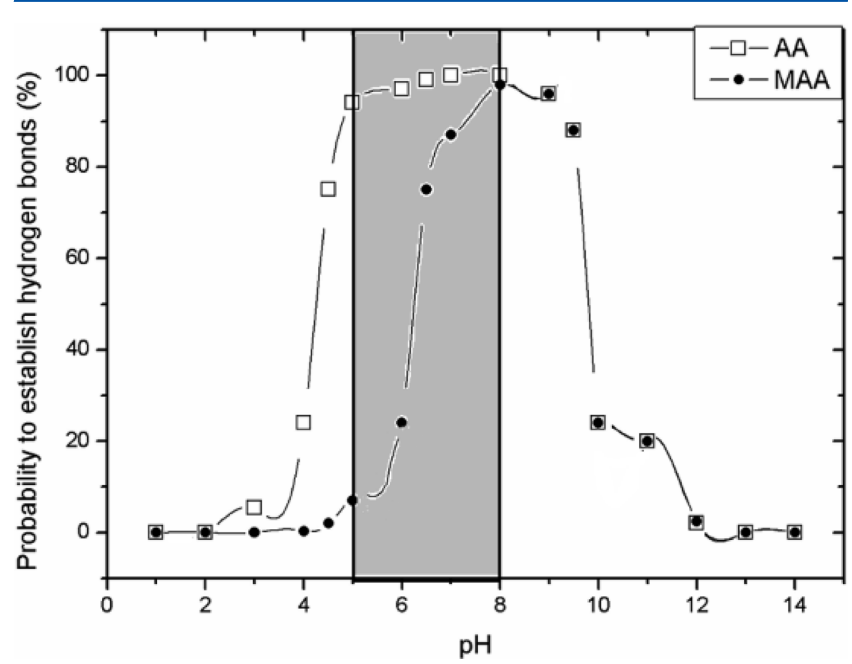

Figure 3. Percentage of histamine bound by MIP synthesized from MAA and AA monomers as calculated by the combinatorial affinity model. The gray area corresponds to the typical $\mathrm{pH}$ range in the intestinal tract $\left(\mathrm{pH} \mathrm{5-8).}{ }^{37}\right.$

Figure 3 shows the probability of hydrogen bond formation for the MAA and AA MIP in a broad $\mathrm{pH}$ range ( $\mathrm{pH} 1-14)$. With these MIPs, it is not possible to perform measurements in strongly basic environments; however, this is outside the scope of our research. Around neutral $\mathrm{pH}$, both MIPs show a high theoretical binding probability. As previously mentioned, the MAA MIP has a very low binding capacity at $\mathrm{pH}<7$ and is therefore not suitable for detection of histamine in acidic environments. In contrast to this, the newly developed MIP based on AA has a theoretical binding probability of still $94 \%$ at $\mathrm{pH} 5$, which is a significant improvement. We will now also demonstrate experimentally that histamine can be bound with a high affinity and selectivity at both neutral and mildly acidic pHs on the basis of the AA MIP. Furthermore, when combined with a refined sensor setup, we will show that it is possible to detect histamine in bowel fluids from the small intestines.

\section{EXPERIMENTAL SECTION}

Chemical Reagents. Ethylene glycol dimethacrylate (EGDM), methacrylic acid (MAA), acrylic acid (AA), and dimethylsulfoxide (DMSO) were purchased from Acros (Geel, Belgium). Prior to polymerization, the stabilizers in the MAA and EGDM were removed by filtration over alumina. Azobusisobutyronitrile (AIBN) was purchased from Fluka (Buchs, Switzerland). The target molecule histamine was obtained from Sigma Aldrich. Histidine, nicotine, serotonin, and betahistine, which are analogues of histamine and were used to test the selectivity, were obtained from Fluka (Buchs, Switzerland). All solvents were of analytical grade. They were purchased from Acros (Geel, Belgium) and used without further purification. The polyphenylenevinylene (PPV) derivative, $\mathrm{OC}_{1} \mathrm{C}_{10} \mathrm{PPV}$, which served as the immobilization layer on the impedimetric sensor MIP and nonimprinted polymer (NIP) electrodes, was synthesized via the sulfinyl precursor route. ${ }^{40}$ Besides MIP sensors, this PPV derivative can also be used for other bioanalytical applications, e.g., as an immobilization layer for antibodies. ${ }^{41}$ All chemical and physical properties of the conjugated polymer were in agreement with previously reported data. A homemade $1 \times$ phosphate buffered saline (PBS) solution was used for the impedance measurements. The human histamine ELISA test was obtained from Gentaur Molecular Products (Kampenhout, Belgium, product number CSB E07042h).

MIP Synthesis. As mentioned in the introduction, it is necessary to use a monomer with a lower $\mathrm{p} K_{\mathrm{a}}$ to detect histamine in acidic environments. Therefore, acrylic acid (AA) with a $K_{\mathrm{a}}$ value of 4.5 was selected. ${ }^{39}$ The corresponding MIP was synthesized according to the following procedure: First, a mixture of AA (18 mmol), EGDM (72 mmol), and AIBN (0.61 $\mathrm{mmol}$ ) was dissolved in $7 \mathrm{~mL}$ of DMSO together with the template molecule histamine $(9.0 \mathrm{mmol})$. This solution was degassed with $\mathrm{N}_{2}$ and polymerized in a UV oven for $12 \mathrm{~h}$. After polymerization, the bulk polymer was ground and sieved to obtain microparticles with a size smaller than $25 \mu \mathrm{m}$. Finally, the histamine was removed from the MIP powders by Soxhlet extraction with methanol (48 h), a mixture of acetic acid/ acetonitrile $(1 / 1)(48 \mathrm{~h})$, and methanol again $(12 \mathrm{~h})$. The extracted powders were dried in vacuum for $12 \mathrm{~h}$ at room temperature. A nonimprinted polymer (NIP) was synthesized in the same way but without the presence of the target molecule. The selectivity of the MIP was tested by optical batch rebinding experiments using chemically similar structures of histamine, such as betahistine and histidine. Furthermore, serotonin and nicotine were used because they are similar in size. For the impedimetric measurements, a MIP imprinted with betahistine was developed as an alternative test for the selectivity. The MIP was synthesized with the same procedure and same molar ratios, but instead of histamine, betahistine was used as a template molecule. The MIP and NIP powders mentioned here were used for all further batch-rebinding and impedimetric measurements.

Preparation of Bowel Fluid and ELISA Test. Bowel fluid samples from the duodenum were obtained from 3 healthy volunteers, Persons 1, 2, and 3 and divided over $1 \mathrm{~mL}$ Eppendorf tubes. After collection, the tubes were centrifuged with $2000 \mathrm{~g}$ to obtain a clear fluid. The samples were stored at $-80{ }^{\circ} \mathrm{C}$ to prevent degradation. Prior to analysis, the samples were heated up to $37^{\circ} \mathrm{C}$ and divided into different aliquots. One part remained unaltered, while from the other parts the native histamine was removed by extraction. This was done by adding $10 \mathrm{mg}$ of MIP powder to $3 \mathrm{~mL}$ of the bowel fluid. The fluid mixture was shaken for $30 \mathrm{~min}$ to allow full absorption of the native histamine, followed by filtration to remove the MIP 

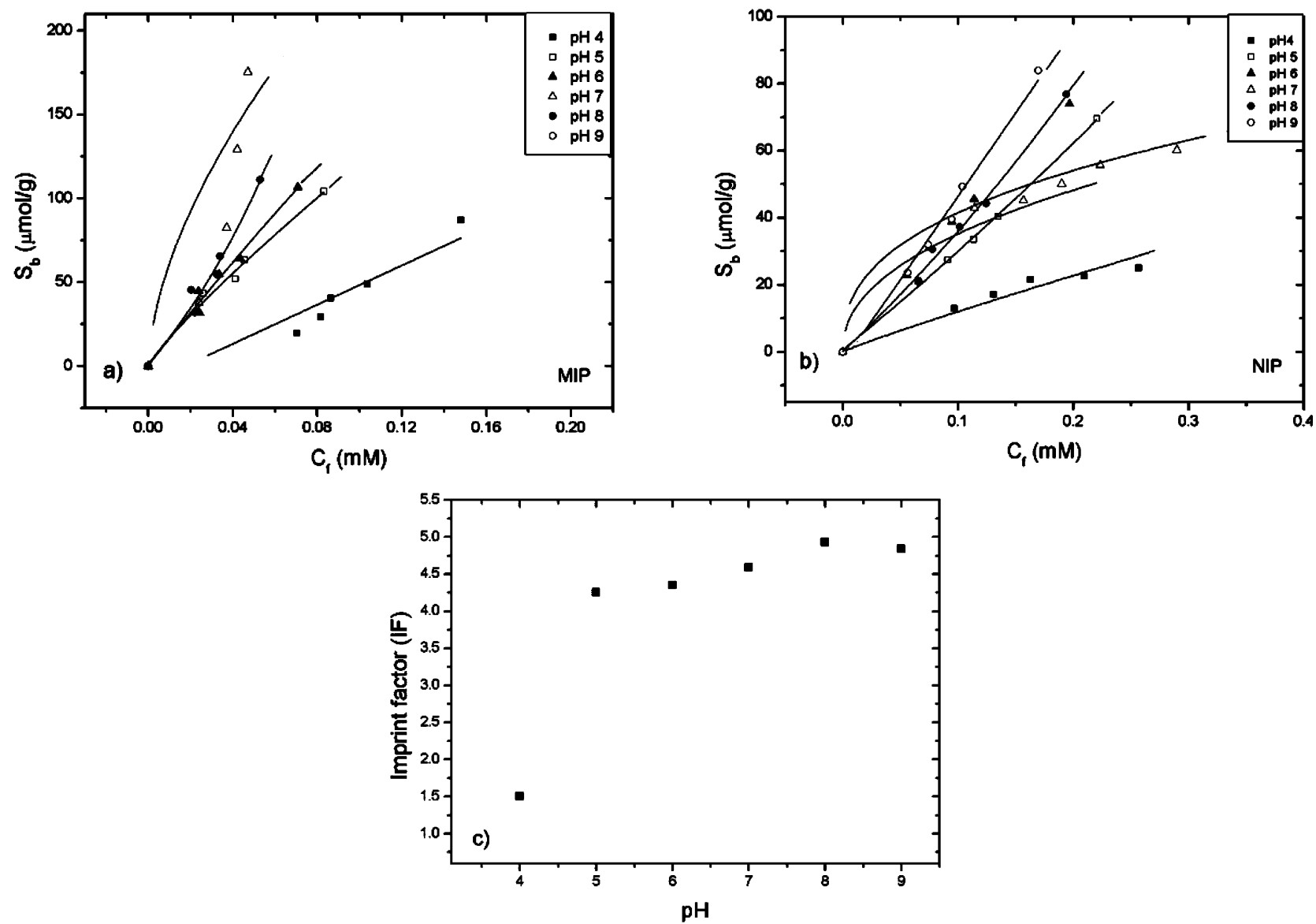

Figure 4. Binding isotherms for the MIP (a) and NIP (b) at $\mathrm{pH} 4-9$. To directly compare the MIP and NIP, the imprint factors $\left(S_{\mathrm{b}} \mathrm{MIP} / S_{\mathrm{b}} \mathrm{NIP}\right)$ at a free concentration of $0.05 \mathrm{mM}$ were calculated in the $\mathrm{pH}$ range of 4-9. (c). The data was fitted with an allometric function of the type $y=a x^{\mathrm{b}}\left(R^{2}\right.$ $=0.95)$.

particles. The resulting extracted bowel fluid served as a reference, and furthermore, upon addition of spiked concentrations of $2.5,5,7.5,25$, and $50 \mu \mathrm{M}$, it was possible to construct a dose-response curve. Subsequently, the impedance response of the unaltered sample was measured with freshly prepared MIP and NIP electrodes. With the dose-response curve, the native histamine concentration could be calculated.

With the unaltered samples, ELISA reference tests were performed with the human histamine ELISA test from Gentaur Molecular Products. All samples were measured in triplicate, and the histamine concentration was calculated by comparing the optical density of the sample to that of the standard curve (Figure S-4, Supporting Information). For Person 1, the histamine concentration was determined to be $870 \mathrm{nM} \pm 60$. For Person 2, this was found to be $500 \mathrm{nM} \pm 50 \mathrm{nM}$, and for Person 3, it was $460 \pm 60 \mathrm{nM}$, respectively.

Impedance-Spectroscopy Platforms. In previous work, we have introduced a differential sensor-cell offering several advantages for biological measurements. ${ }^{42,43}$ With this setup, native serotonin plasma concentrations were measured with relatively small uncertainties and the obtained results were in full agreement with HPLC reference tests. ${ }^{42}$ The flow-through cell is made of PMMA and has an internal volume of $110 \mu \mathrm{L}$. During the measurements, the temperature was fixed to $37 \pm$ $0.02{ }^{\circ} \mathrm{C}$ using a homemade proportional-integral-derivative (PID) $(P=10, I=5, D=0.1)$ controller. The MIP- and NIPcoated electrodes (reference channel) were installed symmetrically with respect to a gold wire serving as a common counter electrode. To construct the electrodes, $1 \times 1 \mathrm{~cm}^{2}$ aluminum substrates were spincoated with conductive $\mathrm{OC}_{1} \mathrm{C}_{10} \mathrm{PPV}$. Equal amounts of the MIP and NIP powder were embedded into the layer by heating up the PPV above its glass transition temperature. The contact area of each electrode with the liquid $\left(28 \mathrm{~mm}^{2}\right)$ was defined by O-rings, and the distance to the gold counter electrode was $1.7 \mathrm{~mm}$. The impedance signals were measured with a homemade, portable system operating in a frequency range of $100 \mathrm{~Hz}$ to $100 \mathrm{kHz}$ with 10 frequencies per decade and a scanning speed of $5.7 \mathrm{~s}$ per sweep. ${ }^{42}$ The amplitude of the AC voltage was fixed to $10 \mathrm{mV}$ under open circuit conditions.

\section{RESULTS AND DISCUSSION}

Optical Batch Rebinding Experiments. Batch rebinding experiments were performed with a Varian Cary 500 UV-visNIR spectrophotometer (Leuven, Belgium). The performance and selectivity of the synthesized MIPs were analyzed under various $\mathrm{pH}$ conditions. Furthermore, at $\mathrm{pH} 5$, the selectivity was evaluated with the analogues nicotine, serotonin, histidine, and betahistine (Figure S-1, Supporting Information).

For the rebinding experiments, $20 \mathrm{mg}$ of MIP or NIP powder was added to $5 \mathrm{~mL}$ of aqueous histamine concentrations in the range between 0.1 and $1.0 \mathrm{mM}$. The $\mathrm{pH}$ of the aqueous solutions was adjusted between $\mathrm{pH} 4$ and 9 by the addition of a hydrochloric acid solution or a sodium hydroxide solution. The resulting suspensions were shaken for $1 \mathrm{~h}$ on a rocking table at 
room temperature. After filtration, the free concentration $\left(C_{\mathrm{f}}\right)$ of histamine was determined by UV-vis spectroscopy. Hereby, the amount of bound histamine per gram of MIP or NIP was calculated $\left(S_{\mathrm{b}}\right)$, and the binding isotherms were constructed. The binding isotherms for the MIP and NIP of AA for $\mathrm{pH} 4-9$ are demonstrated in Figure $4 \mathrm{a}, \mathrm{b}$. Furthermore, the imprint factor at a given concentration $(0.05 \mathrm{mM})$ was calculated. This refers to the amount of target molecules bound per gram of the MIP divided by that of the NIP and is a measure of the specificity $\left(S_{\mathrm{b}} \mathrm{MIP} / S_{\mathrm{b}} \mathrm{NIP}\right)$. The results in the $\mathrm{pH}$ range of 49 are plotted in Figure $4 \mathrm{c}$.

The binding isotherms of the MIP (Figure 4a) and NIP (Figure $4 \mathrm{~b}$ ) show that at $\mathrm{pH} 4$ the binding is mostly aspecific, while from $\mathrm{pH} 5$ to 9 histamine can be detected selectively. This can be explained by the statistical binding analysis model. At $\mathrm{pH} 4$, there is only a low probability (24\%) of hydrogen bond formation. The theoretical probability of binding in the $\mathrm{pH}$ region of 5-9 is above $90 \%$, which indicates that the MIPs are able to bind the target selectively as indeed is observed from experiments. This is confirmed by Figure 4c, which shows the imprint factor, which is significantly lower (1.5) than at $\mathrm{pH} 5-$ 9 ( 4.5). The lower the imprint factor, the less selective is the binding of histamine.

There are several models to describe such binding isotherms. The Langmuir model assumes that all the binding sites are homogeneous, which is clearly not the case with MIPs as there are aspecific and specific affinity sites. To correct for these heterogeneous binding sites, the Langmuir-Freundlich or Freundlich model can be applied. ${ }^{44}$ These models resulted both in a fit with a high linearity coefficient $\left(R^{2}=0.98\right)$. However, it was decided to show the results of the Freundlich model, as this uses one parameter less than the LangmuirFreundlich model (Figure S-5, Supporting Information). These isotherms show the distribution of the affinity sites by plotting the binding energy $\left(K_{\mathrm{i}}\right)$ versus that of the number of sites present $\left(N\left(K_{\mathrm{i}}\right)\right)$. The sites with a low binding affinity correspond to the aspecific binding, while the high affinity binding sites represent the specific binding. The total number of binding sites for the MIP was $114 \pm 0.9 \mu \mathrm{mol} / \mathrm{g}$, while that for the NIP is considerably lower with $21 \pm 0.4 \mu \mathrm{mol} / \mathrm{g}$ (i.e., an imprint factor of 5.4). Hereby, it is proven that the MIP synthesized from acrylic acid, in contrast to the MIP synthesized from methacrylic acid, can specifically detect histamine at $\mathrm{pH}$ value as low as 5 .

To further test the selectivity, the binding of a number of related molecules was investigated. Histidine was used as an analogue in previous articles ${ }^{1,2}$ due to its biological relevance, being the natural precursor of histamine. In its chemical structure, however, there is a significant difference: Histidine is an acid while histamine acts as a base. Therefore, we studied also the response of betahistine, which is chemically more similar to histamine. The only difference is that the amine group of the histamine molecule is substituted by a methyl group (S-1). The binding isotherms obtained with histamine and the analogues are presented in Figure S-2 of the Supporting Information. From this graph, we can observe that the MIPs bind no more of the chosen analogues than the reference NIP binds histamine, and therefore, the selectivity of the MIP is proven. Furthermore, as betahistine binds relatively the most to the MIP, this was chosen as an analogue for the impedance measurements.

Impedance Spectroscopy in PBS Buffer. Histamine occurs mostly in acidic fluids, such as saliva, stomach fluid, and gastric fluid. It is of clinical relevance to measure in gastric fluid, as an increase in concentration could be a possible marker of irritable bowel syndrome (IBS). ${ }^{11,12}$ The normal histamine concentration ranges from 500 to $1000 \mathrm{nM}$, which was determined by ELISA tests (Preparation of Bowel Fluid and ELISA Test). The $\mathrm{pH}$ lies between $\mathrm{pH} 5$ and 7.5, meaning that it can vary from slightly acidic to slightly basic. ${ }^{38}$ Before directly measuring biological fluid, the specificity and selectivity was tested in phosphate buffer solution. To cover the entire $\mathrm{pH}$ range of bowel fluids, measurements were performed at $\mathrm{pH} 5$ and 7.

MIP and corresponding NIP particles were immobilized onto the aluminum electrodes with the procedure described by $\mathrm{R}$. Thoelen et al. ${ }^{45}$ By optical microscopy in combination with image processing (Image J software), the surface coverage was determined to be $27 \% \pm 2.0$ for the MIP and $26 \% \pm 3.0$ for the NIP-loaded electrode. Therefore, the precondition for differential measurements, having identical particle loadings, is fulfilled. Next, the flow-through cell was filled with PBS buffer. After stabilizing the cell with PBS (respectively $\mathrm{pH} 5$ or 7) for $45 \mathrm{~min}$, increasing concentrations $(50-1000 \mathrm{nM})$ of histamine were added. The corresponding dose-response curves at a frequency of $316 \mathrm{~Hz}$ are shown in Figure 5. This frequency was

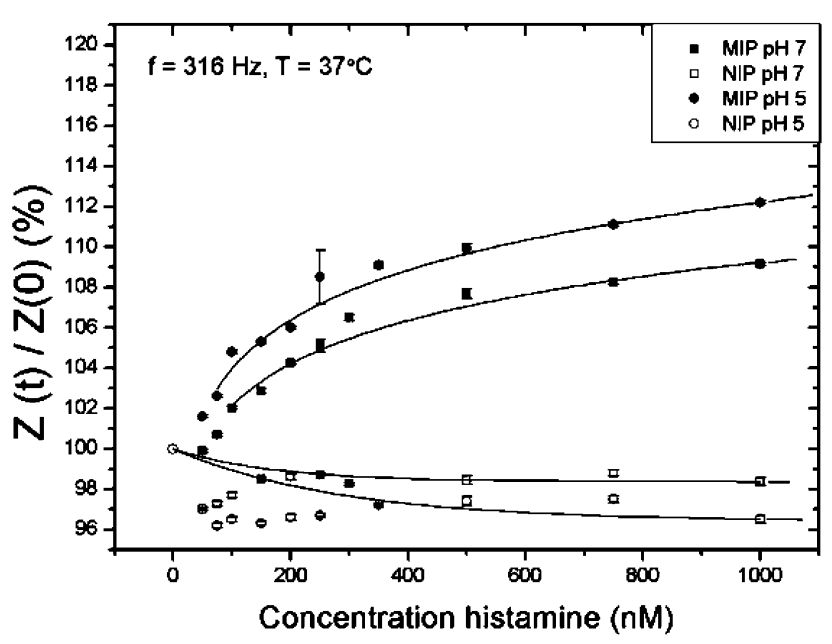

Figure 5. Dose-response curve for MIP and NIP exposed to increasing concentrations of histamine in $\mathrm{PBS}$. At $\mathrm{pH} 7$, data points are shown as solid squares (MIP) and open squares (NIP). At pH 5, the data points are shown are solid circles (MIP) and open circles (NIP). The error bars are indicated, but if applicable, they can be smaller than the symbol size. The used fit was allometric $\left(y=a x^{\mathrm{b}}\right.$, with $\left.R^{2}=0.98\right)$.

selected for two reasons. First, the signal was very stable with only a standard deviation of $0.1 \%$ on the impedance. This ensures a high signal-to-noise ratio, which is approximately 10 at a concentration of $50 \mathrm{nM}$ in PBS, $\mathrm{pH} 5$. Additionally, we can make an estimation of the detection limit. The limit of detection is commonly defined as three times this standard deviation. Hereby, a detection limit of $15 \mathrm{nM}$ is achieved in buffer solution. This is well below the physiologically relevant concentration, which is $500 \mathrm{nM}$ or higher. Second, it was previously demonstrated that the effect upon binding is mainly capacitive, $^{38}$ and therefore, especially, the low frequency regime should be investigated.

The impedance data for each concentration were normalized with respect to a starting value of $100 \%$ pure $\mathrm{PBS}$, prior to addition of the target molecule. After the addition step, the 
sensor was left to stabilize for $10 \mathrm{~min}$. The response value was then obtained by averaging five data points with an interval of 1 min. Hereby, the measuring time was not significantly prolonged, and impedance data scattering was reduced to a minimum.

The impedance results confirmed that the MIP based on AA monomers can detect histamine at $\mathrm{pH}$ 5. In the $0-400 \mathrm{nM}$ range of histamine in $\mathrm{PBS}$ with a $\mathrm{pH} 5$, the dose-response results can be represented well with a linear fit $\left(R^{2}=0.99\right)$. For the physiologically relevant concentration range (500-1000 $\mathrm{nM})$, the data is best represented with an allometric fit $\left(R^{2}=\right.$ 0.98 ) which is due to an increasing occupation of the binding sites. However, there is still a significant difference between the impedance response at $500 \mathrm{nM}(109.9 \% \pm 0.2)$ compared to $1000 \mathrm{nM}(112.2 \% \pm 0.1)$, which allows discrimination between normal and elevated values of histamine.

To test the selectivity, impedance measurements were performed within the same concentration range for betahistine (0-1000 nM) as was done for histamine. Additionally, histamine measurements in the presence of an excess of 1000 times serotonin were performed, which did not significantly alter the obtained results. To test the cross selectivity, a MIP was synthesized using betahistine as the template molecule. The protocol was kept the same as for histamine; for the exact recipe, we refer to MIP Synthesis. This MIP was also incorporated into the sensor setup, and subsequently, impedimetric measurements were performed with increasing betahistine concentrations $(0-750 \mathrm{nM})$. The obtained results at a frequency of $316 \mathrm{~Hz}$ are shown in Figure S-3 of the Supporting Information. As the binding is significantly less than that of the MIP, we can conclude that we can measure histamine specifically and selectively in the desired $\mathrm{pH}$ range $\mathrm{e}^{5-8}$ of biological samples. In the rare case that the $\mathrm{pH}$ of a patient's sample is lower than 5 , one can adjust the $\mathrm{pH}$ by $\mathrm{NaOH}$ addition or by dilution in order to perform the analysis within the specified $\mathrm{pH}$ range of the sensor. For measurements in highly acidic samples, one may also consider MIPs synthesized from a monomer with a lower $\mathrm{p} K_{\mathrm{a}}$ value.

Histamine in Bowel Fluid and ELISA Tests. As a final step, the histamine concentration in real biological samples was investigated. Patient samples from the duodenum were collected and prepared according to Preparation of Bowel Fluid and ELISA Test. To perform the measurements, the cell was first filled with the extracted (nonspiked) bowel fluid of Person 1. The cell was allowed to stabilize for 90 min until a $0.1 \%$ noise ratio was achieved. Subsequently, spiked plasma samples were introduced one by one via a pumping system. After waiting each time for $20 \mathrm{~min}$, the impedance results were determined of the MIP and NIP and averaged over 5 data points. The impedance values of the MIP-NIP response, normalized to nonspiked extracted plasma at $316 \mathrm{~Hz}$, are given in Figure 6.

The impedance change upon exposure to a given histamine concentration is less pronounced than the measurements performed in PBS buffer. A possible explanation for this could be the nonspecific absorption of proteins and bile acids onto the electrode, which partially block the nanocavities. However, there is still a clear MIP-NIP difference with increasing concentrations, as the differential (MIP-NIP) signal in Figure 6 shows. This can be excellently described with an allometric fit. With this experimental dose-response curve, initial (unextracted) bowel fluid concentrations can be measured and the corresponding histamine concentrations

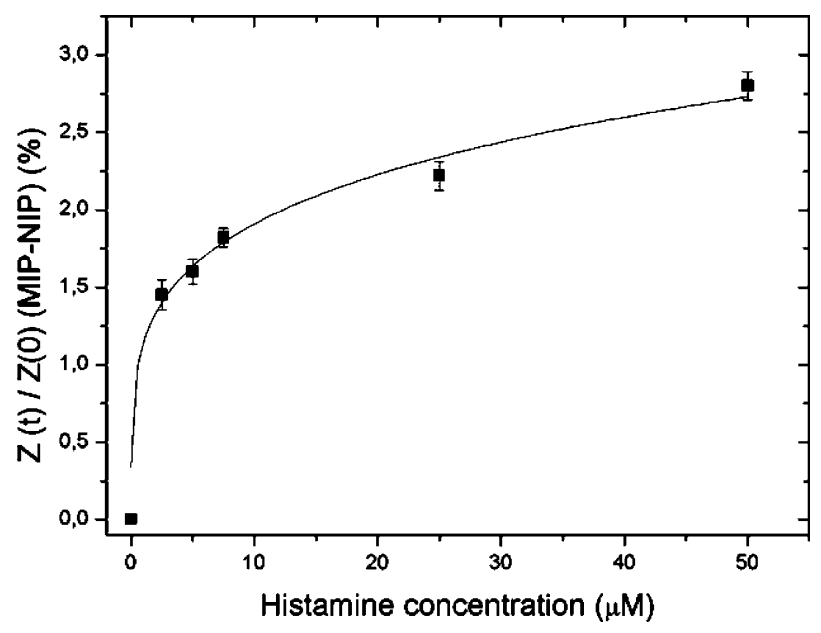

Figure 6. Normalized MIP-NIP response of the extracted bowel fluid of Person A spiked with 2.5, 5, 7.5, 25, and $50 \mu \mathrm{M}$ histamine. The graph is fitted with an allometric function $\left(y=a x^{b}\right)$ with parameters $a$ $=1.14, b=0.22$, and $R^{2}=0.97$. Unextracted bowel fluid resulted in an increase of $0.86 \%$, which corresponds to a value of $800 \mathrm{nM} \pm 90$. With ELISA reference tests, a value of $870 \mathrm{nM} \pm 60$ was found.

were determined for Persons 1, 2, and 3 (Table 1). As an example, in the case of Person 1, an impedance increase of

Table 1. pH and Histamine Concentrations As Determined by the Sensor Setup and Reference ELISA Tests for Bowel Fluid Samples of Persons 1, 2, and 3

\begin{tabular}{cccc} 
persons & $\mathrm{pH}$ & $\begin{array}{c}\text { sensor histamine } \\
\text { concentration }(\mathrm{nM})\end{array}$ & $\begin{array}{c}\text { ELISA histamine } \\
\text { concentration }(\mathrm{nM})\end{array}$ \\
P1 & 5 & $800 \pm 90$ & $870 \pm 60$ \\
P2 & 6 & $570 \pm 70$ & $500 \pm 50$ \\
P3 & 6 & $500 \pm 60$ & $460 \pm 60$ \\
\hline
\end{tabular}

$0.86 \% \pm 0.9$ was found which corresponds to an initial concentration of $800 \mathrm{nM} \pm 90$. For Person 2 and Person 3, the histamine concentrations were, respectively, $570 \mathrm{nM} \pm 70$ and $500 \mathrm{nM} \pm 60$. To validate the results, reference ELISA tests were performed. As Table 1 shows, the results obtained by the sensor and the ELISA tests are nicely within the statistical error range. The $\mathrm{pH}$ was estimated using universal $\mathrm{pH}$ paper, which indicates that the samples are, as was expected, mildly acidic.

\section{CONCLUSIONS}

Histamine is a biogenic amine which mainly occurs in acidic fluids, such as saliva and gastric fluid. Commonly, detection is performed by techniques such as HPLC or ELISA. Sensor platforms with MIPs as synthetic receptors present a fast and low-cost alternative to these traditional techniques; however, previously developed MIPs exhibited $\mathrm{pH}$-dependent binding behavior which complicated binding in acidic environments. We have proposed a statistical binding analysis model to explain this $\mathrm{pH}$-dependent response and, on the basis of theoretical calculations, developed a MIP capable of detecting histamine at acidic pHs. These theoretical calculations were supported by UV-vis batch rebinding experiments, which demonstrated specific and selective detection of histamine in the required $\mathrm{pH}$ range. With impedance spectroscopy as the read-out technique, detection could be performed in the physiologically relevant concentration range. Three intestinal fluid patient samples were measured, and the determined 
histamine concentrations were in nice agreement with ELISA reference tests. Summarizing, we have developed a fast and lowcost method to detect histamine selectively in bowel fluids with the possibility of transferring the techniques to other analytes in an array format.

\section{ASSOCIATED CONTENT}

\section{S Supporting Information}

Information about the statistical binding model and the selectivity of the used MIPs. This material is available free of charge via the Internet at http://pubs.acs.org.

\section{AUTHOR INFORMATION}

\section{Corresponding Author}

*Address: Hasselt University, Institute for Materials Research IMO, Wetenschapspark 1, B-3590 Diepenbeek/Belgium. Phone: 0032-11-268876. Fax: 0032-11-268899. E-mail: marloes.peeters@uhasselt.be.

\section{Author Contributions}

The manuscript was written through contributions of all authors. All authors have given approval to the final version of the manuscript.

Notes

The authors declare no competing financial interest.

\section{ACKNOWLEDGMENTS}

This work was supported by the Life-Science Initiative of the Province of Limburg, the Special Research Funds BOF of Hasselt University, and the Erasmus Programme of the European Union. The authors gratefully acknowledge technical support by H. Penxten, J. Soogen, J. Baccus, H. Bové, M. Peters, M. De Meyer, and N. Tüylüoglu. Also, we appreciate B. Salden from Maastricht University Medical Center for providing the intestinal fluid samples and Dr. L. Tolhuizen from Philips Research, Eindhoven, The Netherlands, for his help on the statistical binding model analysis.

\section{REFERENCES}

(1) Bongaers, E.; Alenus, J.; Horemans, F.; Weustenraed, A.; Lutsen, L.; Vanderzande, D.; Cleij, T. J.; Troost, F. J.; Brummer, R.-J.; Wagner, P. Phys. Status Solidi A 2010, 207, 837-843.

(2) Horemans, F.; Alenus, J.; Bongaers, E.; Weustenraed, A.; Thoelen, R.; Duchateau, J.; Lutsen, L.; Vanderzande, D. Sens. Actuators, B 2010, 148, 392-398.

(3) Dale, H. H.; Laidlaw, P. P. J. Physiol. 1910, 41, 318-44.

(4) Paul, W. Fundamental Immunology, $2^{\text {nd }}$ ed.; Raven Press: New York, 1984; pp 716-720.

(5) Metcalfe, D.; Baram, D.; Mekori, Y. Physiol. Rev. 1997, 77, 103379.

(6) Rang, H.; Dale, M.; Ritter, J.; Gardner, P. Pharmacology, $3^{\text {rd }}$ ed.; Churchill Livingstone: New York, 1995; pp 226-229.

(7) Harsing, L. G., Jr.; Nagashima, H.; Duncalf, D.; Vizi, E. S.; Goldiner, P. L. Clin Chem. 1986, 32, 1823-1827.

(8) Lin, R. Y.; Schwartz, L. B.; Curry, A.; Pesola, G. R.; Hee, H. S.; Bakalchuk, L.; Tenenbaum, C.; Westfal, R. E. J. Allergy Clin. Immunol. 2000, 106, 65-71.

(9) Schwartz, J. C.; Pollard, H.; Quach, T. T. J. Neurochem. 1980, 35, 26-33.

(10) Lehane, L.; Olley, J. Int. J. Food Microbiol. 2000, 58, 1-37.

(11) Barbara, G.; Stanghellini, V.; De Giorgio, R.; Cremon, C.; Cottrell, G. S.; Santini, D.; Pasquinelli, G.; Morselli-Labate, A. M.; Grady, E.F.; Bunnett, N. W.; Collins, S. M.; Corinaldesi, R. Gastroenterology 2004, 126, 693-702.

(12) Wood, J. D. Gut 2006, 55, 445-447.
(13) Chhabra, Y. Z.; Li, H.; Alkhouri, A. E.; Blake, Q.; Armour, C. L.; Hughes, J. M. Eur. Respir. J. 2007, 29, 861-870.

(14) Adlesic, M.; Verdrengh, M.; Bokarewa, M.; Dahlberg, J.; Foster, S. J.; Tarkowski, A. Scand. J. Immunol. 2007, 65, 530-537.

(15) Jackson, J. A.; Riordan, H. D.; Neathery, B. S. J. Orthomol. Psychiatry 1998, 13, 236-240.

(16) Yoshitake, T.; Ichinose, F.; Yoshida, H.; Todoroki, K.; Kehr, J.; Inoue, O.; Nohta, H.; Yamaguchi, M. Biomed. Chromatogr. 2003, 17, $509-516$

(17) Keyzer, J. J.; Wolthers, B. G.; Muskiet, F. A.; Breukelman, H.; Kauffman, H. F.; De Vries, K. Anal. Biochem. 1984, 139, 474-481.

(18) Ujike, A.; Ishikawa, Y.; Ono, M.; Yuasa, T.; Yoshino, T.; Fukumoto, M.; Ravetch, J. V.; Takai, T. J. Exp. Med. 1999, 10, 15731579.

(19) Sarada, B. V.; Rao, T. N.; Tryk, D. A.; Fujishima, A. Anal. Chem. 2000, 72, 1632-1638.

(20) Bitziou, E.; O’Hare, D.; Patel, B. A. Anal. Chem. 2008, 80, $8733-8740$.

(21) Bitziou, E.; Patel, B. A. Am. J. Physiol. Gastrointest. Liver Physiol. 2012, 303, 396-403.

(22) Mochizuki, T.; Yamatodani, A.; Okakura, M.; Takemura, M.; Inagaki, N.; Wada, H. Naunyn-Schmiedeberg's Arch. Pharmacol. 1991, 343, 190-195.

(23) Itoh, Y.; Oishi, R.; Nishibori, M.; Saeki, K. J. Neurochem. 1991, 56, 769-774.

(24) Mosbach, K. Trends Biochem. Sci. 1994, 19, 9-14.

(25) Piletsky, S. A.; Parhometz, Y. P.; Lavryk, N. V.; Panasyuk, T. L.; El'skaya, A. V. Sens. Actuators, B 1994, 19, 629-631.

(26) Ramanavicius, A.; Finkelsteinas, A.; Cesiulis, H.; Ramanaviciene, A. Bioelectrochemistry 2010, 79, 11-16.

(27) Wulff, G. Trends Biotechnol. 1993, 11, 85-87.

(28) Arshady, R.; Mosbach, K. Chem. Phys. 1981, 182, 687-692.

(29) Owens, K.; Karlsson, L.; Lutz, E. S. M.; Andersson, L. I. TrAC, Trends Anal. Chem. 1999, 18, 146-154.

(30) Sellergren, B.; Allender, C. J. Adv. Drug Delivery Rev. 2005, 57, $1733-1741$.

(31) Spivak, D. A. Adv. Drug Delivery Rev. 2005, 57, 1779-1794.

(32) Tong, A.; Dong, H.; Li, L. Anal. Chim. Acta 2002, 466, 31-37.

(33) Allender, C. J.; Richardson, C.; Woodhouse, B.; Heard, C. M.; Brain, K. R. Int. J. Pharm. 2000, 195, 39-43.

(34) Pietrzyk, A. S.; Suriyanarayanan, S.; Kutner, W.; Chitta, R.; D'Souza, F. Anal. Chem. 2009, 81, 2633-2643.

(35) Jenik, M.; Schirhagl, R.; Schirk, C.; Hayden, O.; Lieberzeit, P.; Blaas, D.; Paul, G.; Dickert, F. Anal. Chem. 2009, 81, 5320-5326.

(36) Trikka, F.; Yoshimatsu, K.; Ye, L.; Kyriakidis, D. Amino Acids 2012, DOI: $10.1007 /$ s00726-012-1297-8.

(37) Evans, D. F.; Pye, G.; Bramley, R.; Clark, A. G.; Dyson, T. J.; Hardcastle, J. D. Gut 1988, 29, 1035-1041.

(38) Izumrudov, E. K.; Sukhishvili, S. A. Biomacromolecules 2005, 6, $1782-1788$

(39) Fujiwara, M.; Grubbs, R.; Baldeschwieler, J. D. J. Colloid Interface Sci. 1997, 185, 210-216.

(40) Louwet, D.; Vanderzande, J.; Gelan, A. Synth. Met. 1995, 69, $509-510$.

(41) Cooreman, P.; Thoelen, R.; Manca, J.; vandeVen, M.; Vermeeren, V.; Michiels, L.; Ameloot, M.; Wagner, P. Biosens. Bioelectron. 2005, 10, 2151-2156.

(42) Van Grinsven, B.; Vanden Bon, N.; Grieten, L.; Murib, M.; Janssens, S. D.; Haenen, K.; Schneider, E.; Ingebrandt, S.; Schöning, M. J.; Vermeeren, V.; Ameloot, M.; Michiels, L.; Thoelen, R.; De Ceuninck, W.; Wagner, P. Lab Chip 2011, 11, 1656-1663.

(43) Peeters, M.; Troost, F. J.; Van Grinsven, B.; Horemans, F.; Alenus, J.; Murib, M. S.; Keszthelyi, D.; Ethirajan, A.; Thoelen, R.; Cleij, T. J.; Wagner, P. Sens. Actuators, B 2012, 171, 602-610.

(44) Umpleby, R. J.; Baxter, S. C.; Rampey, A. M.; Rushton, G. T.; Chen, Y. Z.; Shimizu, K. D. J. Chromatogr., B: Anal. Technol. Biomed. Life Sci. B 2004, 804, 141-149. 
(45) Thoelen, R.; Vansweevelt, R.; Duchateau, J.; Horemans, F.;

D'Haen, J.; Lutsen, L.; Vanderzande, D.; Ameloot, M.; vandeVen, M.;

Cleij, T. J.; Wagner, P. Biosens. Bioelectron. 2008, 23, 913-918. 